\title{
Tumor blanco de la rodilla
}

\section{White tumour of knee}

\author{
Rachid Bouchentouf ${ }^{1}$
}

Paciente de sexo femenino de 19 años de edad, sin antecedentes de tuberculosis pulmonar ni exposición a pacientes bacilíferos. Consulta por dolor en rodilla derecha de 1 año de evolución de característica progresiva acompañado de edema. Al examen físico se observó una rodilla derecha con aumento de volumen en cara anterior y posterior, crepitación durante la flexoextensión. En los exámenes auxiliares: hemograma con 11.480 leucocitos por $\mathrm{mm}^{3}$, neutrófilos $83,4 \%$, linfocitos $9,5 \%$, hemoglobina 9 $\mathrm{g} / \mathrm{dl}$, proteína C reactiva $30 \mathrm{mg} / \mathrm{dl}$. La serología para el VIH fue negativa y la radiografía de tórax fue normal. La radiografía de la rodilla derecha mostro aumento focalizado de partes blandas. La ecografía de la rodilla derecha mostró derrame articular y aumento de volumen de partes blandas periarticular. Se realizó artrocentesis obteniendo un líquido de características inflamatorias concluyente con el diagnóstico de artritis séptica.
Se inició terapia antibiótica endovenosa sin mejoría clínica. La resonancia magnética reportó signos compatibles con sinovitis importante y lesión osteolítica en la meseta tibial externa (Figuras 1 A, B).

Se realizó limpieza quirúrgica y drenaje de la rodilla. El estudio de biopsia reveló la presencia de granulomas con células epitelioides y con necrosis caseosa (Figura 2).

PCR por micobacteria fue positiva confirmando el diagnóstico de tuberculosis de la rodilla.

Se inició un tratamiento para tuberculosis con lo que se observó evolución favorable.

La tuberculosis osteoarticular, considerada poco frecuente, se estima que ocurre en el 1,5\% al 3\% de los pacientes con tuberculosis. Es la tercera localización osteoarticular detrás de columna y cadera.

El gran aumento de volumen y la poca intensidad de los signos inflamatorios otorgan la denominación de tumor blanco.

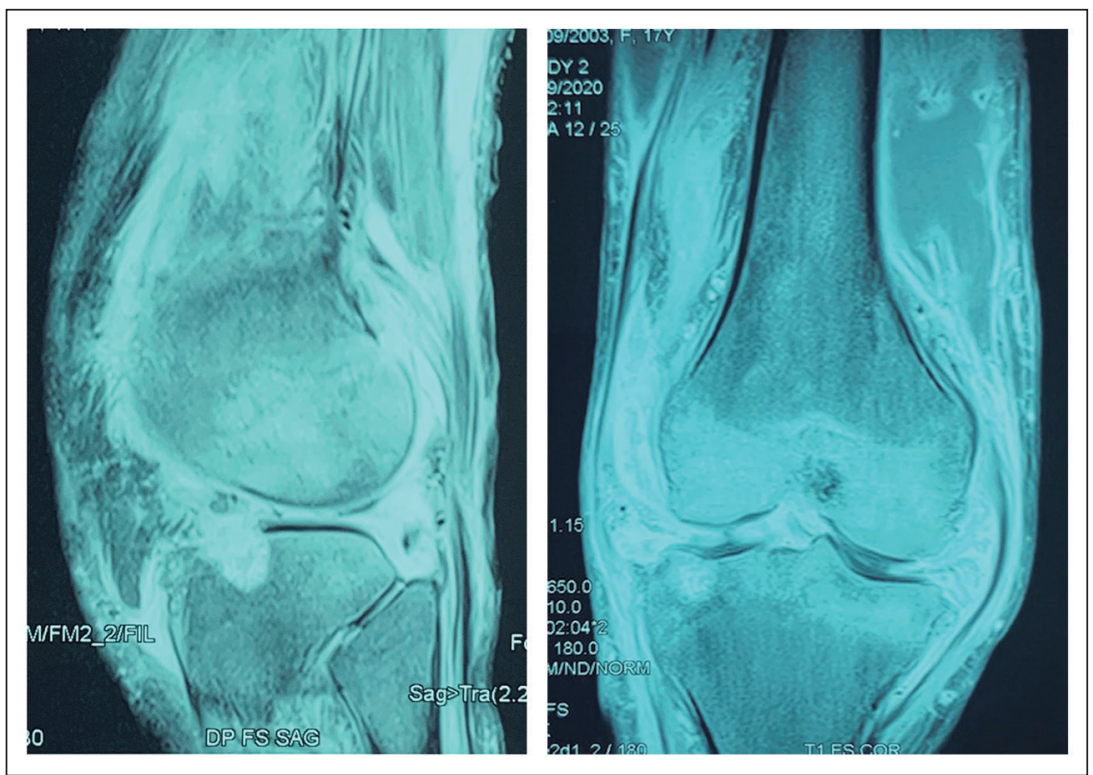

Figura 1. RM de rodilla evidenciando sinovitis y lesión osteolítica en meseta tibial externa.
'Servicio de Neumología, Hospital Militar Avicena, Marrakech. Marruecos.

Recibido 2020-09-29 y aceptado 2020-10-08

Correspondencia a:

Dr. Rachid Bouchentouf rachidbouchentouf513@ gmail.com 
Figura 2. Biopsia de intervención quirúrgica.

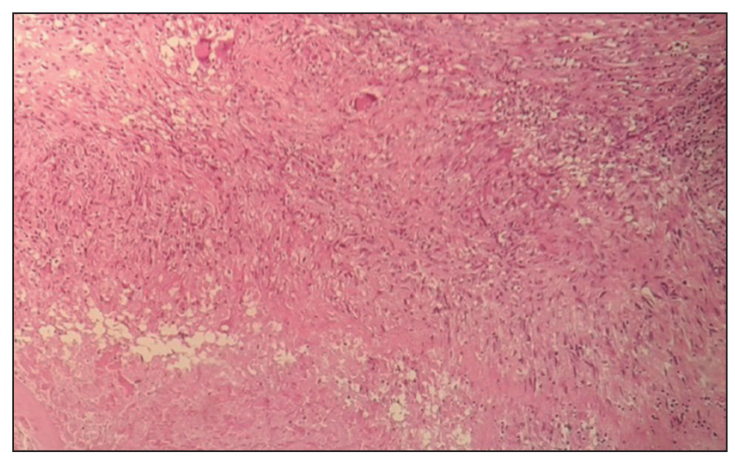

\section{Bibliografía}

1. Tull SM. General principles of osteoarticular tuberculosis. Clinical
Orthopaedics related Research 2002;398:11-9.

2. Hoffman EB, Allin J, Boyd JA, Leisegang F. Tuberculous of the

\section{Responsabilidades éticas}

Protección de personas y animales. Los autores declaran que para esta investigación no se han realizado experimentos en seres humanos ni en animales.

Confidencialidad de los datos. Los autores declaran que en este artículo no aparecen datos de pacientes.

Conflictos de interés: no hay.

knee. Clinical Orthopaedics

Related Research 2002;398:100-6. doi: 10.1097/00003086-20020500000014. 